\title{
Differential expression of living mammary epithelial cell subpopulations in milk during lactation in dairy cows
}

\author{
M. Baratta, ${ }^{* 1}$ M. G. Volpe, ${ }^{*}$ D. Nucera, $†$ G. Gabai, $¥$ N. Guzzo, $\ddagger$ M. Faustini,§ and E. Martignani ${ }^{*}$ \\ *Department of Veterinary Sciences, Largo Braccini 2, University of Torino, 10095 Grugliasco (TO), Italy \\ †Department of Agricultural, Forest and Food Sciences, University of Torino, 10095 Grugliasco (TO), Italy \\ †Department of Comparative Biomedicine and Food Science, University of Padova, 35020 Legnaro (PD), Italy \\ $\S$ Department of Veterinary Medical Sciences, University of Bologna, 40064 Ozzano Emilia (BO), Italy
}

\section{ABSTRACT}

Epithelial cells are shed into milk during lactation, and although they generally reflect the cellular characteristics of terminally differentiated luminal cells, previously the detection of more primitive cells was described in human milk where a cell population of epithelial lineage was detected expressing markers typical of progenitor cells. In this investigation, we report the development of flow cytometry analysis to allow multiparametric assessment of mammary epithelial cells observed in milk. Cells collected from milk samples of 10 healthy dairy cows were directly analyzed for 6 different markers: CD45, CD49f, cytokeratin 14, cytokeratin 18, presence of nucleus, and cell viability. Milk samples were collected in 3 different periods of lactation: early lactation $(\mathrm{EL}=\mathrm{d} 0-30)$, mid-lactation (ML $=\mathrm{d}$ 90-120), and late lactation ( $\mathrm{LL}=210-250)$. Here we identify the differential expression of precursor or differentiated cell markers (or both) in mammary epithelial cells present in bovine milk. Myoepithelial cells, as indicated by cells staining positively for cytokeratin $14^{+} /$cytokeratin $18^{-}$, were observed to increase from EL to LL with a high correlation with nuclear staining inferring potential proliferative activity. Furthermore, a significant increase in $\mathrm{CD}_{4} 9 \mathrm{f}^{+}$and cytokeratin $14^{+} / \mathrm{cy}-$ tokeratin $18^{+}$positive cells was observed in LL. This assay is a sensitive approach for evaluating the variations in the frequency and features of living epithelial cells, whose reciprocal balance may be significant in understanding mammary gland cellular function throughout lactation. These observations suggest that mammary epithelial cell immunophenotypes could be investigated as biomarkers for mammary gland function in dairy cows.

Key words: milk, bovine, epithelial cell, cell precursor

Received January 30, 2015.

Accepted June 23, 2015.

${ }^{1}$ Corresponding author: mario.baratta@unito.it

\section{INTRODUCTION}

Heterogeneous cell populations are present within the mammary secretions of all mammals. In most animals, immune cell types are predominant, in particular lymphocytes, polymorphonuclear neutrophils, and macrophages. Most studies of the cellular fraction of milk report the total count of somatic cells without taking into account the cell viability and cell types. Bovine species have a relatively lower percentage of epithelial cells observed in milk compared with humans (Boutinaud and Jammes, 2002). Mammary epithelial cells (MEC) are also found in milk, caused by shedding during the lactation phase, but the range of cell frequency may differ from total SCC if only the live cell fraction is analyzed. The identification of milk epithelial cells with the features of viable and mature alveolar epithelial cells has been reported. In milk, immune cells are generally accepted as a defense against inflammation or infectious diseases (or both) of the gland. However, very little is known with respect to the epithelial compartment shed in milk, and appreciable suppositions have been made concerning the origin and regulation of these cells (Boutinaud and Jammes, 2002). A renewed interest in this observation has occurred following the discovery that epithelial cells are present that have some immunophenotypes previously associated with precursor cells, and in milk from humans (Cregan et al., 2007; Thomas et al., 2011). In those studies, it has been described how human milk presents different cell populations exhibiting epithelial characteristics (identified by the detection of different cytokeratins; CK) but also expressing specific markers of progenitor cells such as nestin or $\mathrm{p} 63$.

The functional mammary cellular unit is a multicellular complex system organized into alveolar structures connected by a common ductal system. Cell types include an inner layer of $\mathrm{CK}_{1} 8^{+}$luminal cells and an outer layer of $\mathrm{CK}_{1} 4^{+}$myoepithelial cells. The luminal cells in the alveoli can produce milk, whereas the contractile myoepithelial cells are responsible for forcing 
the secreted milk to the teat cistern (Martignani et al., 2010).

Cells in milk have been demonstrated to be able to generate cell colonies of different mammary cell subsets. The functional role of these cells has been postulated to affect neonatal development and breast pathology (Hassiotou et al., 2013; Twigger et al., 2013).

In dairy science, the total amount of somatic cells, usually called SCC, in milk is affected by different factors, such as species, breeds, lactation phase, milk yield, individual animal differences, and management practices (Rupp et al., 2000). Both SCC and composition affect milk quality, but their relationship is not always apparent apart from the case of high SCC corresponding to a high concentration of neutrophils in milk. Usually, it is difficult to analyze cell composition because SCC is a total count that does not consider the concentration of any other cell types present in the secretion (Li et al., 2014).

In recent years, some studies of somatic cells by flow cytometry reported new understanding of the cell subpopulation organization, in particular for immune cells populations (Piepers et al., 2009; Albenzio and Caroprese, 2011). To our knowledge, however, few studies have investigated epithelial subpopulations in relation to the stage of lactation.

We described a 6-color immunophenotyping assay to investigate different living epithelial cell subpopulations present in 3 different phases of lactation in dairy cows. This approach provides the opportunity to further investigate the modification of these cells according to the physiological and pathological state or age of the animal, which may have some effect on production of milk quality.

\section{MATERIALS AND METHODS}

\section{Farms and Animals}

The trial was conducted at the farm of the Department of Veterinary Medical Science, University of Bologna (Ozzano Emilia, BO, Italy) and conducted according to European animal care guidelines. The experimental procedures were approved by the Ethics Committee of the University of Bologna. Cows in the transition period (from $21 \mathrm{~d}$ before the expected calving to $7 \mathrm{~d}$ after calving) were housed in a group pens, then moved to a free-stall pen for the rest of lactation. Cows were fed long grass hay and a concentrate mixture (on average $3 \mathrm{~kg}$ of concentrate for every $7 \mathrm{~kg}$ of hay) before calving and received a total mixed ration after calving, distributed once a day in the morning. After forestripping into a foremilk cup, paper tissues were used for udder cleaning. Water was available ad libitum.

\section{Study Design}

The general udder health status of all lactating cows was determined by analyzing the SCC. Based on these data, 10 Holstein-Frisian cows in good condition were chosen to analyze with apparently healthy mammary glands with low SCC values $(<100,000$ cells $/ \mathrm{mL})$. Samples were collected from 3 different periods: first period of lactation or early lactation (EL), d 0 to 30 after parturition; mid-lactation (ML), d 90 to 120 after parturition; and late lactation (LL), d 210 to 250 after parturition.

\section{Milk Sampling and Processing}

Quarter foremilk samples were obtained in accordance with the Veterinary Services Standards of the Italian National Health Service, branch of the Ministry of Health. Before morning milking, teats were scrubbed with $70 \%$ ethanol and the first 2 strips of milk were discarded. Aliquots of $200 \mathrm{~mL}$ of milk per udder were collected aseptically in a sterile 50-mL BD Falcon tube (BD, Heidelberg, Germany). Ten milliliters was used for SCC assessment according to International Dairy Federation standards (Hamann, 1996). Milk sample were diluted in PBS buffer at a 1:1 ratio to minimize the influence of lipids on pellet formation. Cells were isolated from the milk using 2 repeated centrifugation steps at $200 \times g$ for $15 \mathrm{~min}$ at $4^{\circ} \mathrm{C}$. Pellets were then washed in PBS to a final dilution of 0.5 to $1 \times$ $10^{6}$ cells $/ 100 \mu \mathrm{L}$.

\section{Flow Cytometry Analysis: Sample Processing}

The determination of epithelial subpopulations in milk was carried out utilizing a 6-color flow cytometry assay: nuclear staining was evaluated with Vybrant DyeCycle Ruby stain (Life Technology, Thermo Fisher, Mumbai, India) and living cell with Live/Dead Fixable (Violet) Dead Cell Stain Kit (Life Technology, Thermo Fisher). Anti-CD45 antibody (VMRD Inc., Pullman, WA) was used to gate immune cells, anti-humanCD49f-FITC antibody (anti-h- $\alpha$-integrin-6-FITC, Novus Biological, Littleton, CO), monoclonal anti-CK peptide 18 antibody (clone KS-B17.2, Sigma, St. Louis, MO), and anti-CK14 antibody (Covance, Life Technology, Thermo Fisher). Anti-CD45, anti-CK14, and anti-CK18 antibodies were labeled with, respectively, QDotS525, QDot605, and PE with SiteClick antibody labeling kits according to the manufacturer's instructions (Life Technology, Thermo Fisher). Briefly, 100- $\mu \mathrm{L}$ aliquot of the cell suspension was incubated with $1 \mu \mathrm{L}$ of Violet stain for $30 \mathrm{~min}$ at $4^{\circ} \mathrm{C}$ in the dark; subsequently, cells were washed twice $(250 \times g$ for $5 \mathrm{~min}$ 
at $4^{\circ} \mathrm{C}$ ), then resuspended in PBS $+0.1 \mathrm{mg} / \mathrm{mL}$ of BSA (PBS/BSA), anti-CD45-QDot525 $(0.7 \mu \mathrm{g} / 500,000$ cells), and anti-CD49f-FITC (1 $\mu \mathrm{g} / 500,000$ cell) and incubated for $20 \mathrm{~min}$ at $4^{\circ} \mathrm{C}$ in the dark. After being washed twice in PBS/BSA, cells were fixed and permeabilized using the Intracellular Staining Kit (Invitrogen, Life Technology, Thermo Fisher) according to the manufacturer's instructions. Anti-cytoketarin-18-PE antibody $(0.5 \mu \mathrm{g})$ and anti-CK14-QDot605 antibody (1 $\mu \mathrm{g})$ were incubated in $50 \mu \mathrm{L}$ of adult bovine plasma for $30 \mathrm{~min}$ at room temperature in the dark. Cells were washed twice in PBS/BSA and resuspended in $1 \mathrm{~mL}$ of PBS/BSA. One microliter of Ruby stain was added to each tube and allowed to stand for 5 min at $4^{\circ} \mathrm{C}$, then stored in the dark until analyzed. Stained samples were analyzed using an Attune Acoustic Focusing Cytometer (Life Technologies), equipped with 2 lasers (405 and $488 \mathrm{~nm}$ wavelength). Instrument calibration was checked weekly by use of Attune Performance Tracking Beads (Applied Biosystems, Thermo Fisher). Individual compensation setting for each fluorophore was carried out by antibody-capture beads (AbCAntiMouse Bead kit and AbCAnti-Rat-Hamster Bead kit, Molecular Probes, Life Technologies). Attune Acoustic Cytometer software and BD FACSDiva software were used for data collection and analysis. From 80,000 to 120,000 events were evaluated from each sample. Cells without antibody labeling served as a negative control and were regarded to be a measure for background fluorescence. Fluorescence Minus One control was used to identify data spread due to the multiple fluorescent signals (Baumgarth and Roederer, 2000; Bayer et al., 2007). A first gate (R1) was drawn to define the nuclear staining in all events; a second gate (R2) was drawn to identify the living cells in the somatic cell population, excluding the positive population for violet stain that indicates a dead cell population. The R3 (negative) and R4 (positive) were used for the separation of the immune cell population by using anti-CD45 detection. Subsequently, gating R6, including CD49f positive cells were identified. Finally, R7 and R10 identified CK14positive and CK18-positive subpopulations respectively. Epithelial cells were identified and counted in the total living $\mathrm{CD} 45^{-}$cell population,

\section{Statistical Analysis}

Statistical analysis was performed with SPSS, version 15.0 (SPSS Inc., Chicago, IL). Samples were compared by using nonparametric tests between group differences: differences in cell frequencies between lactation stages were investigated using the Kruskal-Wallis test. To detect variations in cell viability at different time points (EL, ML, and LL), a Mann-Whitney test was used.

\section{RESULTS}

The gating strategy used in this analysis is shown in Figure 1, and based on this strategy, it is possible to observe in parallel the expression of markers of mature differentiated epithelial cells $\left(\mathrm{CK} 14^{+}\right.$for myoepithelial and $\mathrm{CK}_{1} 8^{+}$cells for luminal epithelial compartments, respectively) but also a weak co-expression of both markers in more primitive cells (CK14/CK18 double positive cells). Furthermore, it is possible to identify a specific cell subpopulation expressing CD49f with or without co-expression of CK14 and CK18 mature differentiated markers.

The fraction of the sample analyzed as viable cells was low, ranging from about 4 to $6 \%$ according to lactation phase. The live $\mathrm{CD} 45^{-}$cell population was divided according to the characteristics of the scatter in 2 subpopulations, the first (subset p2) with reduced values of FSC and with low frequency (about 25\% of the subset p1, total population) and a second subset (subset p3) with high values of FSC. Neither of the 2 populations was expressing CD45. The smaller population intensely expresses CK14, but not CK18, whereas the larger population expresses, more weakly, CK18. Interestingly, the "small" CK14 ${ }^{+}$subpopulation showed a markedly higher intensity for the nuclear staining ( $22 \%$ of $\mathrm{P} 1$ ). The $\mathrm{CD} 49 \mathrm{f}^{+} / \mathrm{CD} 45^{-}$cells were detected, but the frequency was low, between 4 and $7 \%$ (see Figure 2).

Figure 3A shows the mean count of total living cells detected in the somatic cell population, identified as CD $45^{-}$cells were from 28 to $75 \%$ according to the stage of lactation in 3 different periods starting from parturition (EL, d 0 to 30; ML, d 90 to 120; and LL, d 210 to 250 ). Figure 3B shows the percentage of epithelial cell subpopulations in EL, ML, and LL groups. Interestingly, we observed a significant difference in the level of myoepithelial cells according to the stage of lactation with an enhancement from 23 to $36 \%(P<$ 0.05). Furthermore, a tendency to increased expression in $\mathrm{CD}_{49 \mathrm{f}^{+}}$and $\mathrm{CK}_{14}{ }^{+} / \mathrm{CK} 8^{+}$positive cells may be observed in LL even if statistical differences were not observed in this study.

\section{DISCUSSION}

In this study, we investigated the frequency of markers for putative primitive and mature epithelial cells and reported that these cell subpopulations are differentially expressed according to the lactation phase. 
A

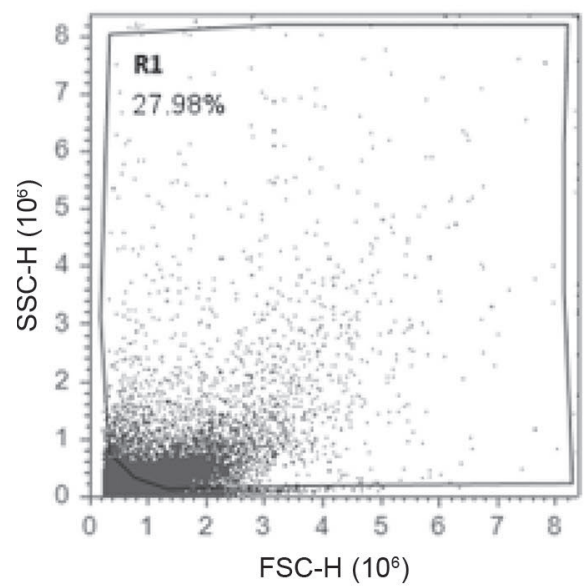

D

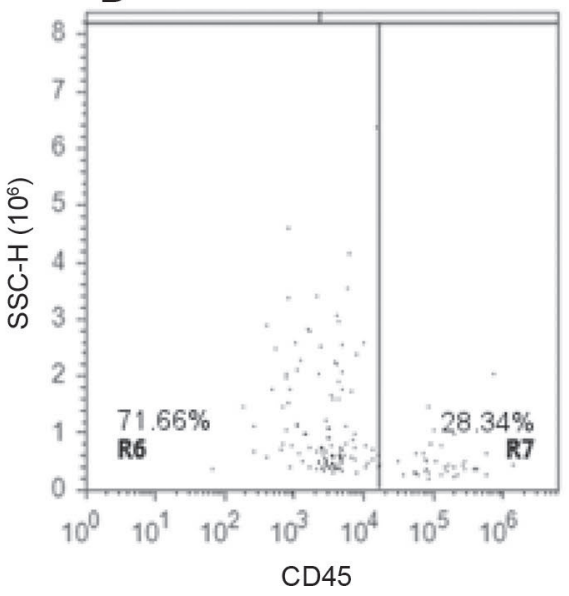

B

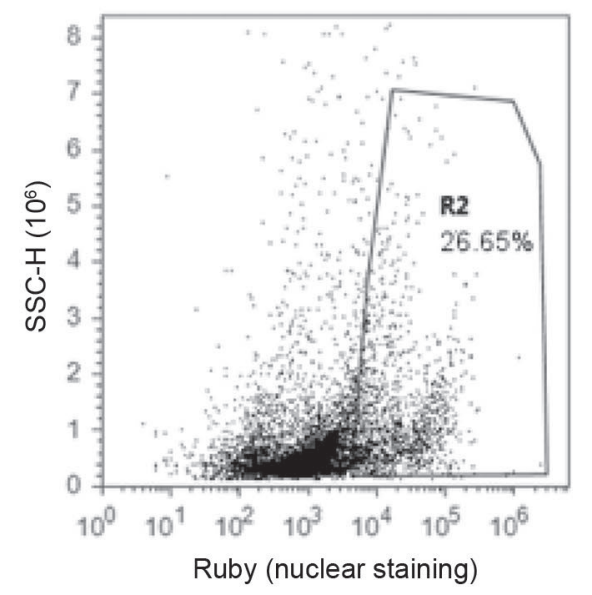

E

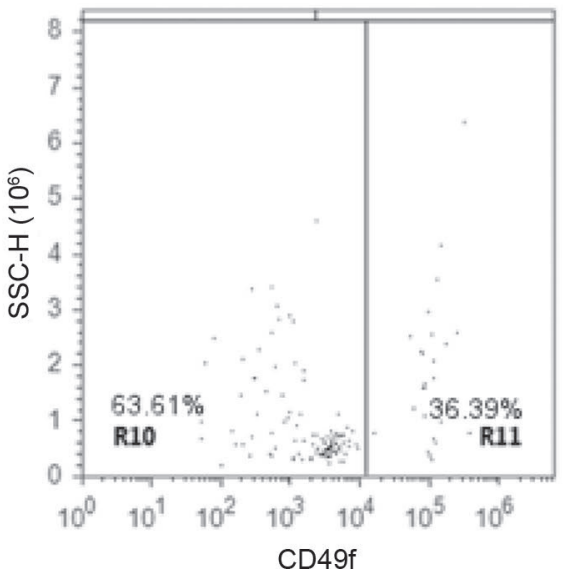

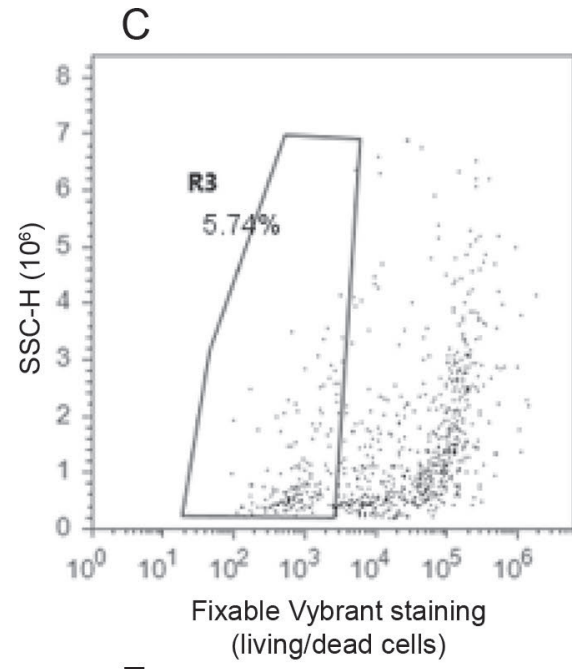

F

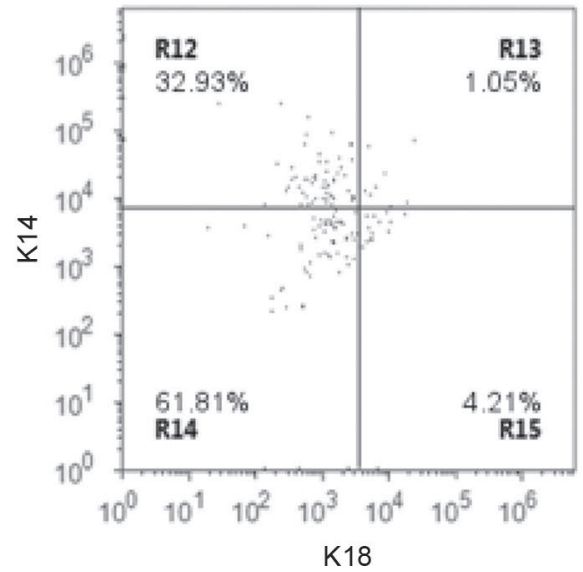

Figure 1. Gating strategy used to separate and count mammary epithelial cells (MEC) from the somatic cells in bovine milk by multicolor flow cytometry assay. (A) Typical distribution in somatic cells in milk on physical parameters in relation to total events population, R1; (B) gated on R2, total cells were identified on the basis of nuclear staining for their specific and positive signal for Vybrant DyeCycle Ruby stain marker; (C) gated on R3 events, total living cells were defined as Live/Dead Fixable Violet Dead Cell Stain negative signal from total R17 cell population; (D) gated R6 to separate MEC (CD45- cells) from immune cells (R7); (E) gated on R11 to obtain CD49f positive cells in MEC; (F) gated on R6 to analyze the differentiated mature MEC (basal compartment cytokeratin (CK)14 positive cells (R12); secreting cells CK18 positive cells (R15); CK14/CK18 double-positive MEC precursor cells (R13).

We focused the analysis on the living cell populations directly in milk samples. The novelty of this multiple analysis resides in the possibility to count simultaneously living MEC in the same sample, allowing a direct comparison between subsets as well as an investigation of their possible co-expression. Key advantages of this type of analysis are that it may be performed by using the same samples used for SCC milk quality tests on dairy farms. To our knowledge few studies have been published on the characterization of this cell fraction, in particular on the identification of primitive epithelial subpopulations within it as most of the studies identify the different types of cells through histological staining. Furthermore, a high nonspecific background fluorescence signal is observed when a cell surface an- tigen analysis is carried out using flow cytometry on a cell sample that contains a high proportion of dead and dying cells (Wing et al., 1990). Thus, we analyzed cell viability in SCC and to determine which are dead and residual in the milk or living, possibly related to the physiological state of the animal. For this purpose, we used a nuclear marker to separate cells from debris and cellular staining for dead cells to gate only living MEC at the specific phase of lactation. In this context we analyzed bovine somatic cells for the epithelial compartment, taking into account primitive epithelial subpopulations. We adopted 3 different antigens that characterize the hierarchy of precursor cells in MEC including CK14, CK18, and CD49f (Martignani et al., 2009; Rauner and Barash, 2012) in addition to a pan 

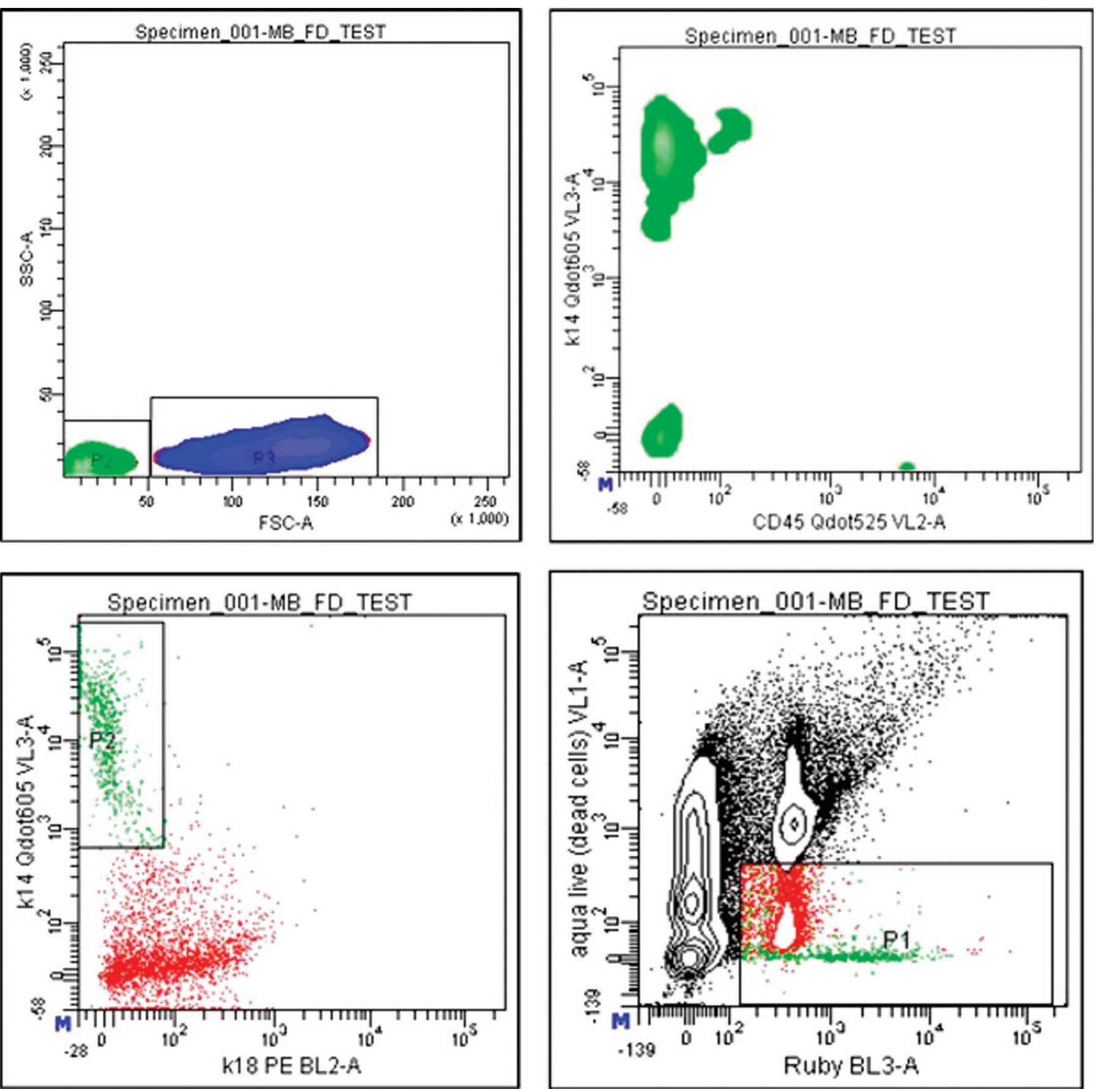

Figure 2. Analysis of CD45-negative cell population: (A) P2 and P3 are CD45 negative subpopulations according to physical parameters; (B) P2 gated for a positive small cytokeratin (CK)14 subpopulation; (C) P3 subpopulation gated for CK18 expression; (D) P1 population gated on nuclear staining signal: CK14 positive cells (green), CK18 positive cells (red).

leukocyte antigen, CD45, or leukocyte common antigen (Boutinaud et al., 2002).

As mentioned, the mammary epithelium is organized as a bilayer, where the inner luminal cells are responsible for milk production, whereas the outer myoepithelial cells have contractile function (Capuco et al., 2002).
The 2 different cell lineages can be identified by the expression of specific markers. Luminal cells are CK18 ${ }^{+} /$ $\mathrm{CK}_{14}{ }^{-}$, whereas myoepithelial cells are $\mathrm{CK} 14^{+} / \mathrm{CK} 18^{-}$. This tissue organization is well conserved among different mammalian species, including human (Eirew et al., 2008), mouse (Mikaelian et al., 2006), goat (Prpar et 

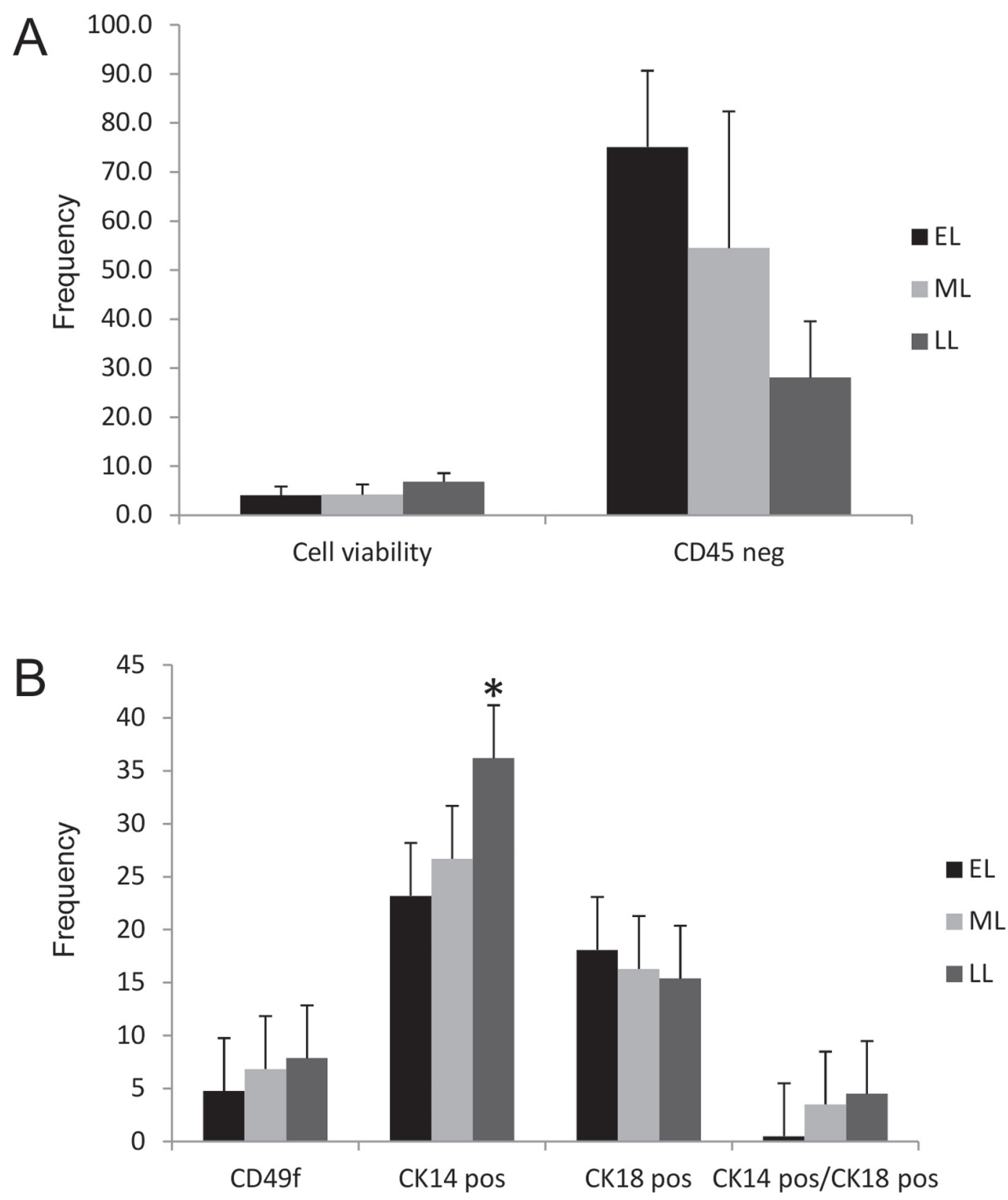

Figure 3. (A) Frequency of cell viability and CD45 negative cell population in bovine milk according to different phases of lactation; (B) frequency of epithelial cell subpopulations in bovine milk according to different phases of lactation. Cell subpopulations are identified according to the positive expression of CD49f, cytokeratin (CK)14, and CK18. EL = 0 to $30 \mathrm{~d}$ after parturition; ML $=90$ to $120 \mathrm{~d}$ after parturition; LL $=210$ to $250 \mathrm{~d}$ after parturition. ${ }^{*} P<0.05$. Error bars represent SD.

al., 2012), and bovine (Capuco et al., 2002; Fridriksdottir et al., 2005). CD49f is part of the laminin-1 receptor and is expressed in the mammary tissue by basal cells. A high CD49f expression has been associated with myoepithelial progenitors and adult mammary stem cells (Stingl et al., 2006; Eirew et al., 2008).

One finding of interest is the increase in the subepithelial CK14 ${ }^{+} / \mathrm{CK}_{1} 8^{-}$cells toward the end of lactation and, also, a trend to greater presence of $\mathrm{CD}_{4} 9 \mathrm{f}^{+}$and
CK14/18 double positive cells. In fact, at this stage, the stimulus for mammary gland remodeling induced by mammogenetic factors regulated by the subsequent pregnancy cannot yet be taken into account; the animals are still lactating, albeit in a decline phase. These cells are the result of lactation in progress and their presence induced by the decline of the luminal cell compartment. The gradual exhaustion of the inner secreting cell layer at the end of lactation may activate a partial activation 
of cell proliferation in the outermost layer. An interesting fact that should receive attention in future studies is the comparison of the number of myoepithelial cells in different lactation periods in the mammary tissue. This comparison could use a functional approach, such as colony-forming cell assay, indicating the frequency of the number of differentiated cells.

The CD49f ${ }^{+}$and CK14/18 double positive cells present in milk may belong to most primitive epithelial cells (mammary precursors) that may be lost during the decline of lactation for some mechanism not yet identified and in this way impoverished the mammary secretory function, which adjusts the number of active secretory cells. We hypothesize that this subpopulation may be considered the signal of a reduction in mammary efficiency. This reduction could have a physiological aspect but different causes should also be considered, such as mammary gland pathologies and management related to the methods of milking. The animals were routinely checked by clinical observation, and no pathology of the mammary gland was detected. For this reason, it would be very interesting to verify with further studies if the increase of this epithelial cell subpopulation is directly correlated with the loss of milk-producing capacity of the mammary gland during the last part of lactation. This hypothesis would propose that this cell population could be used as a biomarker of production efficiency of the mammary gland. The observation of $\mathrm{CK}_{14}{ }^{+}$cells highly correlated with nuclear staining also led us to presume that the DNA content in these cells is significantly as high as cells would be in a proliferative phase. It has been reported previously that basal layer cells, $\mathrm{CK}_{1}{ }^{+}$cells, migrate into the inner layer of the alveolus before starting the proliferative phase. This observation supports the concept that cells residing in the basal layer are the primary proliferative cell population (Ellis and Capuco, 2002). From histological analyses, it has been reported in different species that the lightly staining cell population present in mammary parenchyma may function as mammary stem cells and that light cells accounted for $50 \%$ of the cell proliferation mostly resident in the basal compartment (Chepko and Smith, 1997; Capuco et al., 2002).

The presence of CD49f positive cells, even if in a low number, may be related also to the reduction in the myoepithelial compartment that indicated the modification of the myoepithelial genetic program (Garbe et al., 2012). This integrin has been shown to be a component of a feedback circuit that regulates the myoepithelial phenotype in mammary epithelial cells from humans and mice (Deugnier et al., 1999; LaBarge et al., 2009), suggesting that the basal regulatory machinery may be disrupted in myoepithelial cells, and inappropriately engaged in luminal epithelial cells, during the aging process. Further studies are necessary to further investigate this intriguing hypothesis.

\section{CONCLUSIONS}

In summary, we report the expression of epithelial precursors and fully differentiated cells, highlighting possible variations in the number and features of MEC subsets in milk. We also report evidence that may support the theory that different distributions of MEC subpopulations may provide more detailed information on the physiology of the mammary gland during lactation in dairy cows and, potentially, have an application to evaluate mammary gland functionality.

\section{ACKNOWLEDGMENTS}

This work was supported by PRIN 2010-2011 (project of national interest from the Italian Ministry of Education, Universities and Research, Rome, Italy). Special thanks go to Claudio Ortolani (University of Urbino, Urbino, Italy) for critical review in flow cytometry data. We thank Cristina Cecere (University of Torino, Grugliasco, Italy) for her technical help and John Peter Mazzoglio (University of Torino) for manuscript language revision. None of the authors of this manuscript declare a conflict of interest.

\section{REFERENCES}

Albenzio, M., and M. Caroprese. 2011. Differential leucocyte count for ewe milk with low and high somatic cell count. J. Dairy Res. 78:43-48.

Baumgarth, N., and M. Roederer. 2000. A practical approach to multicolor flow cytometry for immunophenotyping. J. Immunol. Methods 243:77-97.

Bayer, J., D. Grunwald, C. Lambert, J. F. Mayol, and M. Maynadie. 2007. Thematic workshop on fluorescence compensation settings in multicolor flow cytometry. Cytometry B Clin. Cytom. 72:8-13.

Boutinaud, M., and H. Jammes. 2002. Potential uses of milk epithelial cells: A review. Reprod. Nutr. Dev. 42:133-147.

Boutinaud, M., H. Rulquin, D. H. Keisler, J. Djiane, and H. Jammes. 2002. Use of somatic cells from goat milk for dynamic studies of gene expression in the mammary gland. J. Anim. Sci. 80:1258 1269.

Capuco, A. V., S. Ellis, D. L. Wood, R. M. Akers, and W. Garrett. 2002. Postnatal mammary ductal growth: Three-dimensional imaging of cell proliferation, effects of estrogen treatment, and expression of steroid receptors in prepubertal calves. Tissue Cell 34:143-154.

Chepko, G., and G. H. Smith. 1997. Three division-competent, structurally-distinct cell populations contribute to murine mammary epithelial renewal. Tissue Cell 29:239-253.

Cregan, M. D., Y. Fan, A. Appelbee, M. L. Brown, B. Klopcic, J. Koppen, L. R. Mitoulas, K. M. Piper, M. A. Choolani, Y. S. Chong, and P. E. Hartmann. 2007. Identification of nestin-positive putative mammary stem cells in human breastmilk. Cell Tissue Res. 329:129-136.

Deugnier, M. A., M. M. Faraldo, P. Rousselle, J. P. Thiery, and M. A. Glukhova. 1999. Cell-extracellular matrix interactions and EGF are important regulators of the basal mammary epithelial cell phenotype. J. Cell Sci. 112:1035-1044. 
Eirew, P., J. Stingl, A. Raouf, G. Turashvili, S. Aparicio, J. T. Emerman, and C. J. Eaves. 2008. A method for quantifying normal human mammary epithelial stem cells with in vivo regenerative ability. Nat. Med. 14:1384-1389.

Ellis, S., and A. V. Capuco. 2002. Cell proliferation in bovine mammary epithelium: Identification of the primary proliferative cell population. Tissue Cell 34:155-163.

Fridriksdottir, A. J., R. Villadsen, T. Gudjonsson, and O. W. Petersen. 2005. Maintenance of cell type diversification in the human breast. J. Mammary Gland Biol. Neoplasia 10:61-74.

Garbe, J. C., F. Pepin, F. A. Pelissier, K. Sputova, A. J. Fridriksdottir, D. E. Guo, R. Villadsen, M. Park, O. W. Petersen, A. D. Borowsky, M. R. Stampfer, and M. A. LaBarge. 2012. Accumulation of multipotent progenitors with a basal differentiation bias during aging of human mammary epithelia. Cancer Res. 72:3687-3701.

Hamann, J. 1996. Somatic Cells: Factors of Influence and Practical Measure. Pages 9-11 in Mastitis Newsletter, Newsletters of the IDF No. 144.

Hassiotou, F., A. R. Hepworth, T. M. Williams, A. J. Twigger, S. Perrella, C. T. Lai, L. Filgueira, D. T. Geddes, and P. E. Hartmann 2013. Breastmilk cell and fat contents respond similarly to removal of breastmilk by the infant. PLoS ONE 8:e78232.

LaBarge, M. A., C. M. Nelson, R. Villadsen, A. Fridriksdottir, J. R. Ruth, M. R. Stampfer, O. W. Petersen, and M. J. Bissell. 2009 Human mammary progenitor cell fate decisions are products of interactions with combinatorial microenvironments. Integr. Biol. (Camb.) 1:70-79

Li, N., R. Richoux, M. Boutinaud, P. Martin, and V. Gagnaire. 2014 Role of somatic cells on dairy processes and products: A review. Dairy Sci. Technol. 94:517-538.

Martignani, E., P. Eirew, P. Accornero, C. Eaves, and M. Baratta. 2010. Human milk protein production in xenografts of genetically engineered bovine mammary epithelial stem cells. PLoS ONE 5:e13372.
Martignani, E., P. Eirew, C. Eaves, and M. Baratta. 2009. Functional identification of bovine mammary epithelial stem/progenitor cells. Vet. Res. Commun. 33(Suppl. 1):101-103.

Mikaelian, I., M. Hovick, K. A. Silva, L. M. Burzenski, L. D. Shultz, C L. Ackert-Bicknell, G. A. Cox, and J. P. Sundberg. 2006. Expression of terminal differentiation proteins defines stages of mouse mammary gland development. Vet. Pathol. 43:36-49.

Piepers, S., V. S. De, K. Demeyere, B. N. Lambrecht, K. A. De, E. Meyer, and G. Opsomer. 2009. Technical note: Flow cytometric identification of bovine milk neutrophils and simultaneous quantification of their viability. J. Dairy Sci. 92:626-631.

Prpar, S., E. Martignani, P. Dovc, and M. Baratta. 2012. Identification of goat mammary stem/progenitor cells. Biol. Reprod. 86:117.

Rauner, G., and I. Barash. 2012. Cell hierarchy and lineage commitment in the bovine mammary gland. PLoS ONE 7:e30113.

Rupp, R., F. Beaudeau, and D. Boichard. 2000. Relationship between milk somatic-cell counts in the first lactation and clinical mastitis occurrence in the second lactation of French Holstein cows. Prev. Vet. Med. 46:99-111.

Stingl, J., P. Eirew, I. Ricketson, M. Shackleton, F. Vaillant, D. Choi, H. I. Li, and C. J. Eaves. 2006. Purification and unique properties of mammary epithelial stem cells. Nature 439:993-997.

Thomas, E., N. Zeps, M. Cregan, P. Hartmann, and T. Martin. 2011. 14-3-3sigma (sigma) regulates proliferation and differentiation of multipotent p63-positive cells isolated from human breastmilk. Cell Cycle 10:278-284.

Twigger, A. J., S. Hodgetts, L. Filgueira, P. E. Hartmann, and F. Hassiotou. 2013. From breast milk to brains: The potential of stem cells in human milk. J. Hum. Lact. 29:136-139.

Wing, M. G., A. M. Montgomery, S. Songsivilai, and J. V. Watson. 1990. An improved method for the detection of cell surface antigens in samples of low viability using flow cytometry. J. Immunol. Methods 126:21-27. 